\title{
Erratum to: Towards the realization of label-free biosensors through impedance spectroscopy integrated with IDES technology
}

\author{
R. Di Capua $\cdot$ M. Barra $\cdot$ F. Santoro $\cdot$ \\ D. Viggiano $\cdot$ P. Ambrosino $\cdot$ M. V. Soldovieri $\cdot$ \\ M. Taglialatela $\cdot$ A. Cassinese
}

Published online: 24 January 2012

(C) European Biophysical Societies' Association 2012

\section{Erratum to: Eur Biophys J}

\section{DOI 10.1007/s00249-011-0782-4}

The name of one of the co-authors was inadvertently misspelled in the manuscript supplied for publication. The correct name of the seventh author is M. Taglialatela.

The online version of the original article can be found under doi:10.1007/s00249-011-0782-4.

R. Di Capua $(\varangle) \cdot$ D. Viggiano · P. Ambrosino .

M. V. Soldovieri · M. Taglialatela

Health Sciences Department, University of Molise,

Campobasso, Italy

e-mail: roberto.dicapua@unimol.it

R. Di Capua · M. Barra · F. Santoro - A. Cassinese CNR-SPIN and Department of Physical Science,

University of Naples Federico II, Naples, Italy 